\title{
Large-Scale Environmental Conditions Related to Midsummer Extreme Rainfall Events around Japan in the TRMM Region
}

\author{
ATSUSHI HAMADA ${ }^{\mathrm{a}}$ AND YUKARI N. TAKAYABU \\ Atmosphere and Ocean Research Institute, The University of Tokyo, Kashiwa, Japan
}

(Manuscript received 21 September 2017, in final form 17 April 2018)

\begin{abstract}
The precipitation characteristics of extreme events in August determined from 13 years of satellite data around Japan in the TRMM observation region and their relationship with large-scale environmental conditions are examined. Two types of extreme events, extreme rainfall and extreme convective events, are defined in each analysis grid box using maximum near-surface rainfall and maximum 40 -dB $Z$ echo-top height in each event, respectively. There are clear differences in precipitation characteristics between the two types of extreme events. Extreme rainfall events are more organized precipitation systems than the extreme convective events, with relatively lower echo-top heights and very low lightning activity. There are also clear differences in the related environmental conditions, where the environments related to the extreme rainfall events are somewhat convectively stable and very humid in almost the entire troposphere. These facts are consistent with our previous studies and reinforce the importance of warm-rain processes in extremely intense precipitation productions. The environments related to the extreme rainfall events exhibit a zonally extended moist anomaly in the free troposphere from southern China to the east of Japan, indicating that the excessive moisture transported from the west by a large-scale flow may partially play a role in producing environmental conditions favorable for extreme rainfall. On the other hand, the environments related to extreme convective events are not associated with free-tropospheric moisture inflow. The relationships with the tropical cyclones and upper-tropospheric dynamical fields are also examined, and are found to be clearly different between the extreme rainfall events and extreme convective events.
\end{abstract}

\section{Introduction}

Heavy rainfall events trigger natural disasters such as floods and landslides, and cause severe damage to lives and property. It has largely been accepted that intensity and frequency of extreme precipitation have a positive trend in many regions of the world, and will further increase under a warming climate (IPCC 2013). To properly project the future change of extreme precipitation, the relationship between the precipitation characteristics of extreme precipitation events and environmental conditions should be correctly understood. Hamada et al. (2015, hereafter referred to as H15) determined two types of extreme events-extreme rainfall events and extreme convective events-over the tropics and

\footnotetext{
${ }^{\text {a }}$ Current affiliation: Faculty of Sustainable Design, University of Toyama, Toyama, Japan.
}

Corresponding author: Atsushi Hamada, hamada@sus.u-toyama. ac.jp subtropics from long-term measurements from a precipitation radar (PR) on board the Tropical Rainfall Measuring Mission (TRMM) satellite. They demonstrated that there are significant differences in the precipitation characteristics and related atmospheric condition between the two types of extreme events. Their results indicate that a conventional and widely accepted cognition that heavier rainfall comes from stronger convection cannot basically be applied to extremely intense rainfall. The atmospheric environment related to extreme rainfall events is shown to be relatively convectively stable and very moist, especially in the free troposphere.

Previous case studies on heavy rainfall events around the Japan region have focused primarily on the relatively local environments and topographic effects to examine their initiation and maintenance mechanisms, and to correctly reproduce the event by numerical simulations. This approach does make sense because torrential rainfall is mostly caused by active cumulus convection and its initiation is highly associated with the 
inflow and convergence of warm and humid air in the boundary layer. An interesting but seemingly opposing point is that many previous studies indicated that heavy rainfall events in the Japan region that are not directly associated with tropical cyclones are basically associated with dry air in the midtroposphere (e.g., Kato and Goda 2001; Kato and Aranami 2005), whereas H15 indicated very humid conditions there. Unuma and Takemi (2016) also showed that a humid condition similar to H15's result is associated with warm-season convective rainfall events. This apparent contradiction underlines the need for correct understanding of how the midtropospheric moisture determines the precipitation characteristics of heavy rainfall events.

Recently, large-scale moisture transport in the midtroposphere as well as the lower troposphere is being considered as a key factor in the summertime rainfall characteristics. Horinouchi (2014) showed that during midsummer, narrow bands of precipitating area are frequently formed on the southern side of the subtropical jet associated with enhanced low- to midlevel humidity in narrow regions. Yokoyama et al. (2017) demonstrated that a stronger subtropical jet is associated with increased rainfall along the southern side of the jet and a distinct eastward extension of the midtropospheric moist region during the baiu season. Sohn et al. (2013) indicated the relationship of warm-type heavy rainfall events over the Korean peninsula to strong water vapor fluxes along the periphery of the North Pacific high and associated moisture convergences.

There are also some case studies that indicate the relationship between large-scale moisture transport in the midtroposphere and heavy rainfall events. Hirota et al. (2016) examined the environmental condition of a heavy rainfall event in Hiroshima, Japan, on 19 August 2014 , and performed a series of numerical experiments to test sensitivity of the event to free-tropospheric moisture. They found that a so-called atmospheric river (AR; Zhu and Newell 1998; Gimeno et al. 2014; Kamae et al. 2017), which typically exhibits filamentary structure a few hundred kilometers wide and several thousand kilometers in length from the Indochina Peninsula, transports considerable water vapor in the free troposphere and plays a crucial role in producing the excessive rainfall (e.g., Waliser and Guan 2017).

While there are some case studies investigating the relationship between the midtropospheric moisture and extreme rainfall events, very little statistical analysis has been conducted to examine their relationship over the Japan region. To this end, we apply the work by H15 to the southern Japan region in the midsummer to describe the differences in precipitation characteristics and related large-scale environmental conditions between the two types of extreme events determined by H15extreme rainfall events and extreme convective events. We especially focus on the large-scale atmospheric condition for the development of the extreme rainfall events, especially on the midtropospheric moisture inflow. Section 2 describes the data and analysis methods used in this study. Section 3 examines the precipitation characteristics for the extreme rainfall events and extreme convective events. Section 4 examines the largescale environmental conditions related to the two types of extreme events. A summary and discussion are presented in section 5 .

\section{Data and methodology}

The TRMM PR is a unique spaceborne radar that can observe three-dimensional precipitation structures at Ku band (13.8 GHz frequency). The non-sun-synchronous orbit with an inclination of $35^{\circ}$ of the TRMM satellite allows the collection of rainfall data between $\sim 36.5^{\circ} \mathrm{S}$ and $\sim 36.5^{\circ} \mathrm{N}$ at all local times. In this study, we use threedimensional rainfall and attenuation-corrected equivalent radar reflectivity $\left(Z_{e}\right)$ data derived from the PR 2A25 product (version 7; Iguchi et al. 2000, 2009). The product includes vertical profiles of instantaneous rainfall rate and $Z_{e}$ from the near-surface level to $20 \mathrm{~km}$, at a resolution of $250 \mathrm{~m}$ with a footprint of $4.3 \mathrm{~km}$ in diameter (5 km after August 2001), within a swath width of $220 \mathrm{~km}$ (247 km after August 2001). The TRMM satellite has also made lightning measurements by the Lightning Imaging Sensor (LIS). The LIS has a square field of view of $550 \mathrm{~km}$ on a side and viewing time of $\sim 90$ s to estimate the flash rates. In this study, we use geographical locations of observed flashes in the LIS science data (Blakeslee 1998).

A rainfall event database, which is constructed based on the PR 2A25 product and the LIS science data, is used to determine extreme rainfall events and extreme convective events, and to examine their precipitation characteristics. Although a detailed procedure to determine the extreme rainfall events has been described in Hamada et al. (2014), a short description is presented here as a summary. A rainfall event is defined as a set of contiguous pixels with their near-surface rainfall rates exceeding $0.5 \mathrm{~mm} \mathrm{~h}^{-1}$. A removal filter for unnatural extreme precipitation profiles, mainly due to contamination of surface or main lobe clutter, had been applied to the original PR 2A25 dataset before determining the rainfall events (Hamada and Takayabu 2014). In this study, we focus on extreme events in August. This is mainly because we intend to examine the large-scale environmental conditions that are not clearly associated 
with distinct stationary fronts such as the baiu front. Extreme events were determined from 13 months (August 2002-14) of the rainfall event database. The analysis domain is set to the southern Japan region between $127.5^{\circ}$ and $142.5^{\circ} \mathrm{E}$ and between $30^{\circ}$ and $37.5^{\circ} \mathrm{N}$. The extreme events are determined for each $2.5^{\circ} \times 2.5^{\circ}$ grid cell to properly capture regional differences of precipitation characteristics. Two types of extreme events, extreme rainfall events and extreme convective events, are defined as follows. A rainfall event is defined as an extreme rainfall event when the maximum nearsurface rainfall rates $\left(R_{\max }\right)$ are within the corresponding uppermost $0.1 \%$ for the target grid cell. Extreme convective events are defined in a similar manner to determine the extreme rainfall events but using the maximum $40-\mathrm{dB} Z$ height of the $Z_{e}$ instead of nearsurface rainfall rate. Note that every August in the years from 2002 to 2014 (for a total of 13 events) consists only of 403 days, meaning that seemingly less than 1000 define the top $0.1 \%$ events. However, the number of TRMM overpasses at a grid box during the analysis period are about 730,1030 , and 610 at the latitudinal bands of $30^{\circ}-32.5^{\circ} \mathrm{N}, 32.5^{\circ}-35^{\circ} \mathrm{N}$, and $35^{\circ}-37.5^{\circ} \mathrm{N}$, respectively. The average number of observed rainfall events at a TRMM overpass at those latitudinal bands are 5.4, 5.2, and 2.6, respectively. Therefore, the total number of rainfall events is greater than 1000 at all the grid boxes, and the top $0.1 \%$ extreme events can be defined.

Because the extreme rainfall events and extreme convective events are determined independently from the same rainfall event population in each grid cell, some rainfall events may be qualified as both types of the extreme events. Hereinafter, extreme events qualified as extreme rainfall events but not extreme convective events are called R-extreme events, extreme events qualified as extreme convective events but not extreme rainfall events are called $\mathrm{H}$-extreme events, and extreme events determined as both extreme rainfall and convective events are called $\mathrm{RH}$-extreme events. The number of the extracted extreme events are 63,52 , and 10 for R-extreme events, $\mathrm{H}$-extreme events, and $\mathrm{RH}$ extreme events, respectively. Among the determined extreme events, 41, 35, and 10 of R-, H-, and RH-extreme events occurred over the sea.

Environmental conditions related to the extreme events are obtained and examined using the Japanese 55-year Reanalysis Project (JRA-55; Kobayashi et al. $2015)$. We used a 6 -hourly, $1.25^{\circ} \times 1.25^{\circ}$ gridded dataset for the same period as TRMM data used in this study. We basically used a pressure-level dataset that has 27 pressure levels from 1000 to $100 \mathrm{hPa}$, except that potential vorticity data to identify the subtropical jet position were taken from isentropic analysis field at $350 \mathrm{~K}$. To examine the environmental condition related to the extreme events as an anomaly from the normal condition, climatologically averaged 6-hourly atmospheric fields were prepared as follows. First, a Kolmogorov-Zurbenko filter (Yang and Zurbenko 2010), which is essentially an iterated moving average, was applied to daily time series separately for the fixed UTC hours (0000, 0600, 1200, and 1800 UTC). The length of the moving average was set to 9 days and the number of iterations was set to 3 , following the method for calculating the climatological fields used by the Japan Meteorological Agency. Second, the 13-yr average was calculated for each 6-hourly UTC time for each calendar day. These steps generated a 6-hourly climatological atmospheric field. The reason for calculating subdaily climatology was to avoid mixing the diurnal variation with the anomaly fields related to the extreme events. An anomalous atmospheric field related to each extreme event was calculated as the deviation from the climatological field prepared here.

\section{Precipitation characteristics of the extreme events}

We first look at the precipitation characteristics of two types of extreme events around Japan in the TRMM region, and further study some additional precipitation characteristics that have not been examined in H15. Figure 1 shows the locations of extreme events determined in this study. Note that the numbers of extreme events have latitudinal dependence due to the orbital characteristics of TRMM PR, where the number of PR footprints has a sharp peak at around $34^{\circ} \mathrm{N}$ and $34^{\circ} \mathrm{S}$ (Hirose et al. 2017, their Fig. 1). Over land, R-extreme events tend to occur at slightly lower elevations, around $300 \mathrm{~m}$, in many regions, while $\mathrm{H}$-extreme events exhibit less dependence on elevation. Over the ocean, there seems to be no specific area of geographical location.

Composite vertical profiles of $Z_{e}$ (Fig. 2) and rainfall rate (Fig. 3) at the pixel where the maximum nearsurface rainfall rate or the maximum $40-\mathrm{dB} Z$ echo-top height is observed for the R-extreme events or $\mathrm{H}$-extreme events, respectively, also exhibit features consistent with H15. Precipitation-top heights of $\mathrm{R}$-extreme events are generally lower than those of $\mathrm{H}$-extreme events. Important characteristics in the $Z_{e}$ profile below the melting level, as shown in H15, are also observed. That is, $Z_{e}$ of R-extreme events increase downward to the surface but $Z_{e}$ of $\mathrm{H}$-extreme events tend to be vertically aligned. A linear downward 


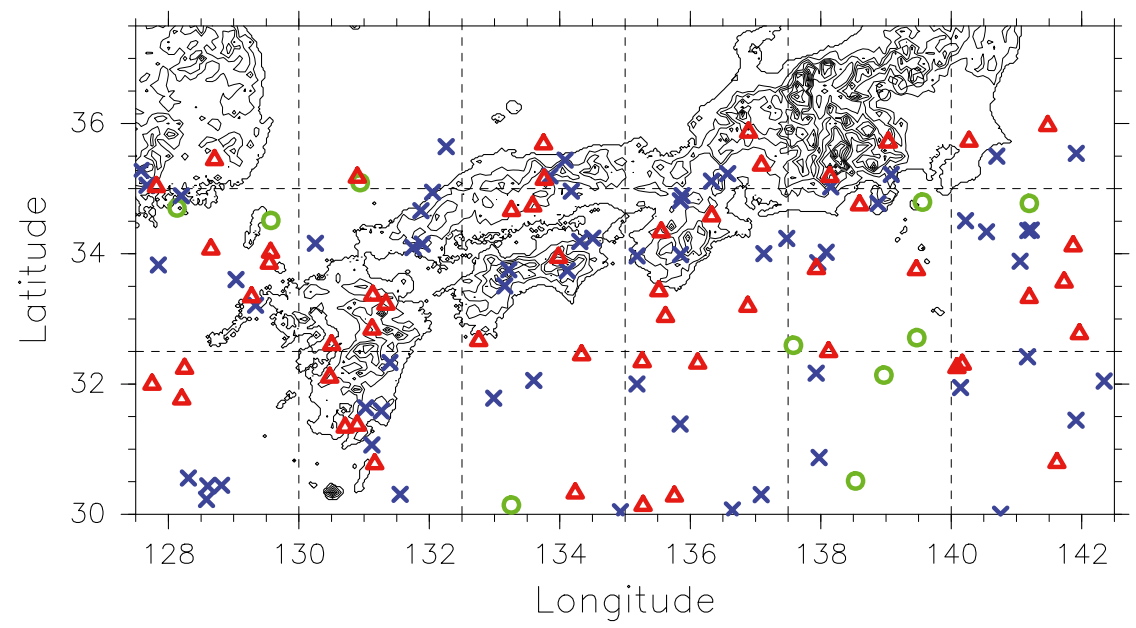

FIG. 1. Locations of the extreme events derived from TRMM PR measurements in August 2002-14. R-only, H-only, and RH-type extreme events are indicated by blue crosses, red triangles, and green circles, respectively. Thin solid contours indicate the elevation every $300 \mathrm{~m}$, derived from the SRTM30 (Farr et al. 2007).

increase of $Z_{e}$ of R-extreme events yields an exponential increase of the rainfall rates (Fig. 3). Such differences imply an importance of warm-rain processes in the precipitation production (H15).

Significant difference is found in the $R_{\max }$ values for the extreme events between $\mathrm{R}$ - and $\mathrm{H}$-extreme events. Figure 4 shows the histograms of the $R_{\max }$ values for $\mathrm{R}$ - and $\mathrm{H}$-extreme events. The solid line shows the cumulative frequency of the $R_{\max }$ values for all rainfall events (regardless of extremity). The 99.9th-percentile value, which is the threshold percentile to determine the extreme rainfall events, corresponds to $115.8 \mathrm{~mm} \mathrm{~h}^{-1}$ as a representative value of the analysis domain. There is a clear difference in the $R_{\max }$ distributions between $\mathrm{R}$ - and $\mathrm{H}$-extremes. The $R_{\max }$ values of $\mathrm{H}$-extreme events distribute between 10 and $100 \mathrm{~mm} \mathrm{~h}^{-1}$, centered around $30-60 \mathrm{~mm} \mathrm{~h}^{-1}$. However, $R_{\max }$ of R-extreme events are much higher, and their lowest end almost corresponds to the highest end of the H-extreme distribution. The percentile values corresponding to the $R_{\max }$ of 30 and $60 \mathrm{~mm} \mathrm{~h}^{-1}$ are 97.6 and 99.3 , respectively, indicating that $\mathrm{H}$-extreme events produce every $\sim 40$ th to 150 th intense rainfall. An important indication from this result is that thresholding values used to statistically define "heavy rainfall" or "intense precipitation" in $1 \mathrm{~h}$ or less in the Japan region, which are generally set around $50-80 \mathrm{~mm} \mathrm{~h}^{-1}$ (e.g., Fujibe 1999; JMA 2017) or 95th99th-percentile values (e.g., Fujibe 2015), include both $\mathrm{R}$ - and $\mathrm{H}$-extreme events, and the precipitation characteristics and related environmental conditions between $\mathrm{R}$ - and $\mathrm{H}$-extreme events might blur into each other.
Several precipitation characteristics of the extreme events are further examined (Fig. 5). R-extreme events are larger and have a higher stratiform-area ratio than $\mathrm{H}$-extreme events (Figs. 5a,b). This indicates that $\mathrm{R}$-extreme events consist of more organized precipitation systems, while $\mathrm{H}$-extreme events are less organized and rather isolated systems. The maximum $40-\mathrm{dB} Z$ echotop heights show almost no overlap between R- and H-extreme events (Fig. 5c), as was also shown in Fig. 2. However, the maximum precipitation-top heights show less noticeable difference between $\mathrm{R}$ - and $\mathrm{H}$-extreme events (Fig. 5d), although the difference is statistically significant at a $95 \%$ confidence level using the Mann-Whitney $U$ test. These contrasting characteristics are reflected in the distributions of flash rate per convective rainfall pixel per minute observed by the LIS, and minimum polarization-corrected temperature at $85 \mathrm{GHz}$ (PCT85) in the extreme event observed by TRMM Microwave Imager (TMI). There is almost no overlap for flash rate distributions between $\mathrm{R}$ - and $\mathrm{H}$-extreme events, whereas the difference is less noticeable for minimum PCT85 (Figs. 5e,f). This indicates that the primary difference in the precipitation characteristics between $\mathrm{R}$ - and $\mathrm{H}$-extreme events is observed in the internal structures of convective clouds, not in the cloudtop heights. This reinforces the hypothesis that warmrainfall processes are important to produce extreme instantaneous rainfall.

\section{Environmental states}

Large-scale environmental conditions related to the two types of extreme events are examined. Figure 6 


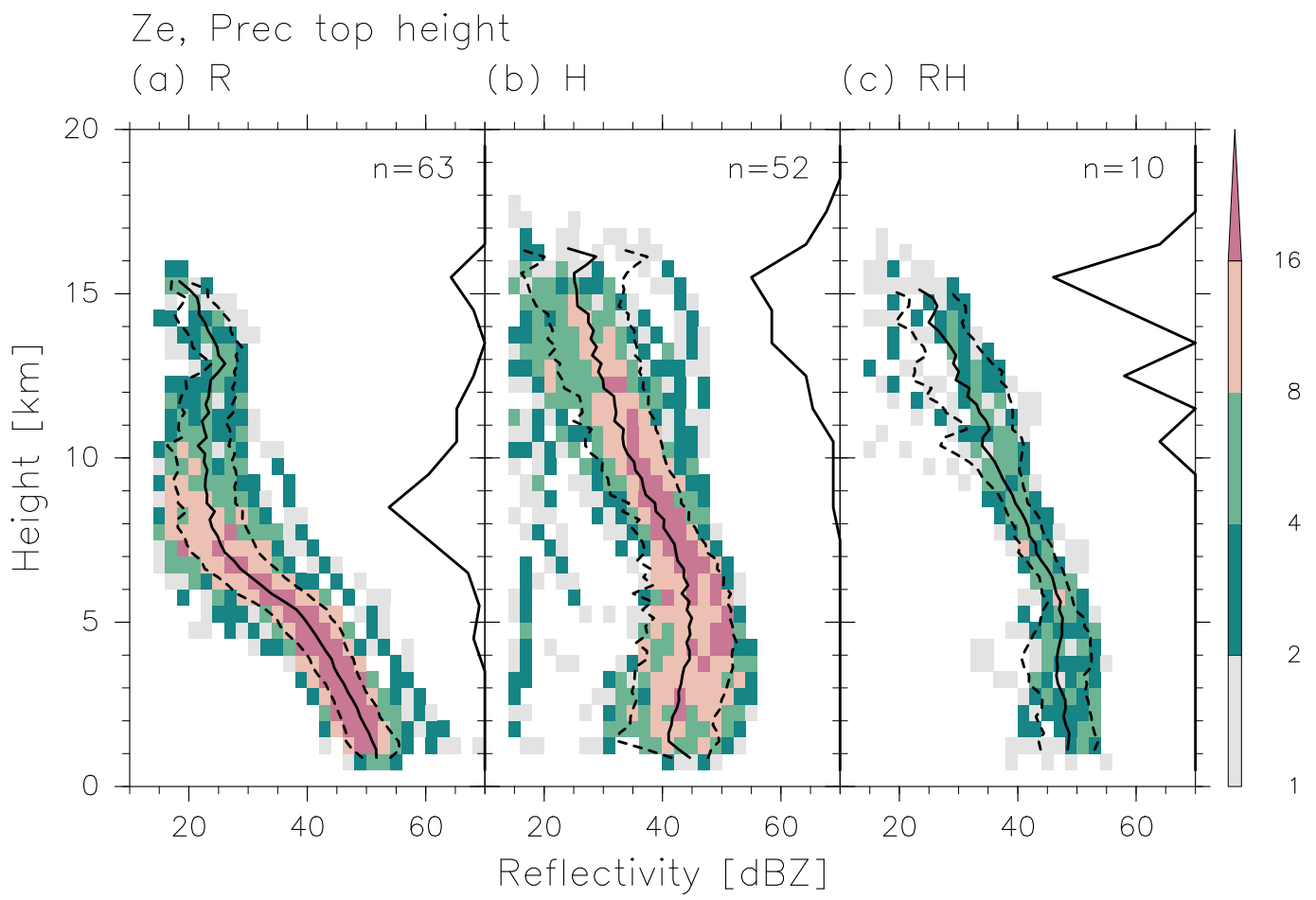

FIG. 2. Composite structures of radar reflectivity at extreme pixels as shown by joint histograms of radar reflectivity and height for (a) R-extreme, (b) H-extreme, and (c) RH-extreme events. Color tones indicate the number of extreme events in each height $-Z_{e}$ bin. Solid and dashed lines indicate the mean and standard deviation range at each height bin, respectively. Line graph in the right of each panel shows relative frequency distribution of precipitation-top heights at the extreme pixels, with the horizontal axis being arbitrarily scaled so that zero and unity of the relative frequency correspond to the rightmost and leftmost of each panel, respectively. The numbers of the corresponding extreme events are indicated.

shows a composite environmental profile for the two types of extreme events; shown are the raw profiles (Figs. 6a-d) and the anomalies from the climatological mean (Figs. 6e-h). The environmental profile for each extreme event making up the composite profile is calculated by bilinear interpolation of the temporally nearest profiles of 6-hourly reanalysis at the surrounding four grid points onto the location of the $R_{\max }$ or highest $40-\mathrm{dB} Z$ echo-top height for R- and $\mathrm{H}$-extreme events, respectively. There are clear differences between the environmental conditions of the R-and $\mathrm{H}$-extreme events, especially in the free troposphere above the 800-hPa level.

For the R-extreme events, the air temperature is colder and warmer than the climatology below and above the $450-\mathrm{hPa}$ level, respectively (Fig. 6e), indicating a somewhat conditionally stable condition in almost the entire troposphere. The equivalent potential temperature is warmer than the climatology in almost the entire troposphere, while it is slightly colder than the climatology below $900 \mathrm{hPa}$ (Fig. 6f). Relative humidity is higher than the climatology in almost the entire troposphere (Fig. 6g). The warmer equivalent potential temperature in the free troposphere is mainly contributed from higher specific humidity (Fig. 6h). In the boundary layer (below the $900-\mathrm{hPa}$ level), the anomaly of equivalent potential temperature for the R-extreme events is slightly negative because of the colder air temperature and the minimal change in the specific humidity. Therefore, in terms of convective instability, the environments related to the R-extreme events have rather stable conditions in the lower troposphere but are slightly more unstable in the free troposphere.

The environmental profiles for the $\mathrm{H}$-extreme events showed contrasting features with those for the Rextreme events. The air temperature is warmer and colder than the climatology below and above $650 \mathrm{hPa}$, respectively (Fig. 6e). The equivalent potential temperature is lower than the climatology throughout almost the entire troposphere (Fig. 6f), because of lower specific humidity at the lower levels and colder air temperature at the upper levels. The relative humidity is lower than the climatology in almost the entire troposphere (Fig. $6 \mathrm{~g}$ ). Both anomaly profiles of the equivalent potential temperature and temperature for the $\mathrm{H}$-extreme events indicate more unstable and stable conditions compared 


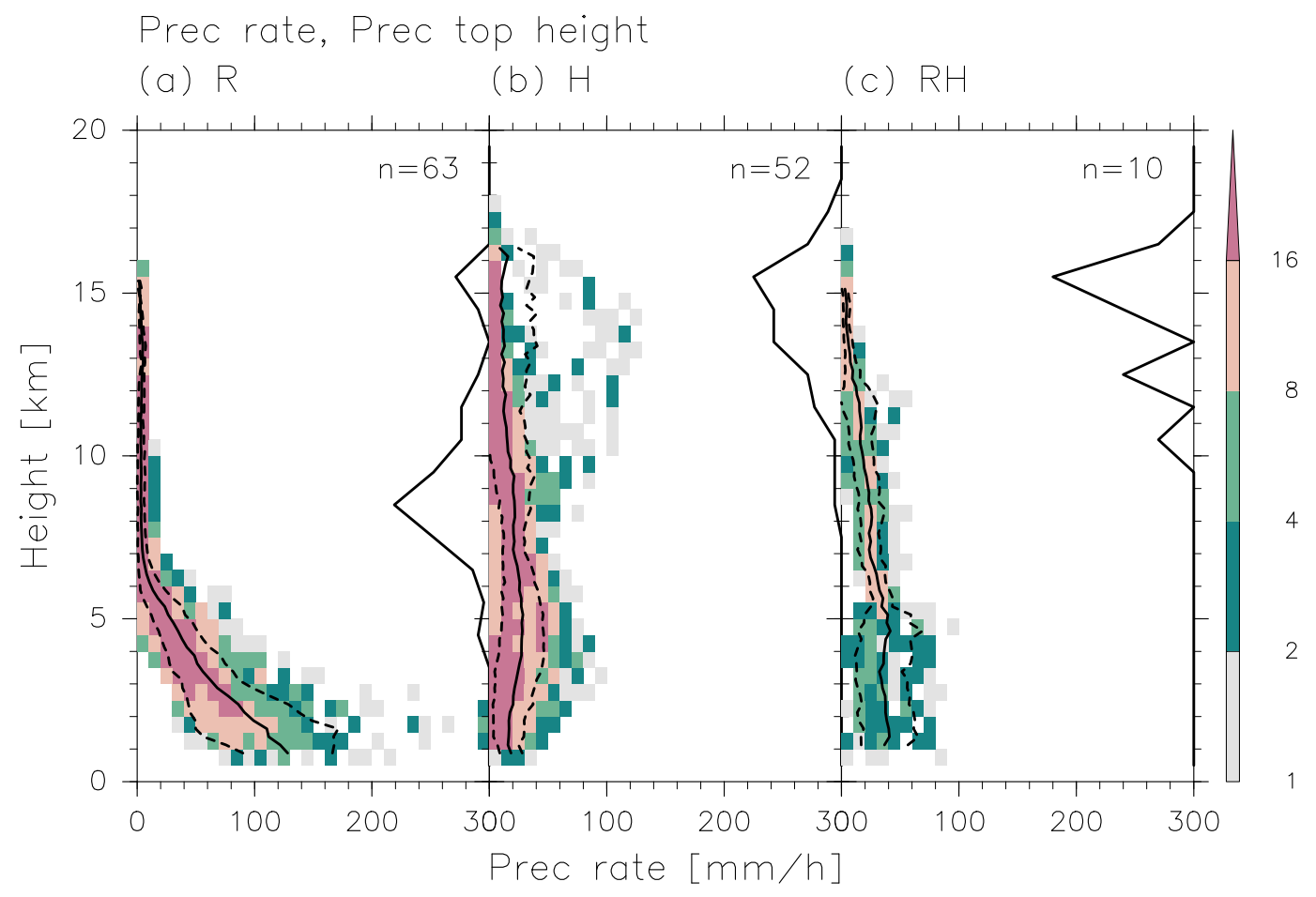

FIG. 3. As in Fig. 2, but for precipitation rate.

to the climatology below and above around $400 \mathrm{hPa}$, respectively.

Such contrasting features between $\mathrm{R}$ - and $\mathrm{H}$-extreme events indicate that related large-scale conditions are different between the lower and middle troposphere. To further examine the difference in the large-scale environments between the lower and middle troposphere, vertically integrated moisture and its horizontal fluxes are defined separately for the free troposphere and the boundary layer. The definitions were $\langle q\rangle_{\mathrm{FT}}$ and $\langle q \mathbf{u}\rangle_{\mathrm{FT}}$, and $\langle q\rangle_{\mathrm{BL}}$ and $\langle q \mathbf{u}\rangle_{\mathrm{BL}}$, respectively. Here the angle brackets denote a mass-weighted vertical integral between two of the pressure levels:

$$
\langle()\rangle=g^{-1} \int_{p_{2}}^{p_{1}}() d p,
$$

where $p_{1}$ and $p_{2}$ are 100 and $800 \mathrm{hPa}$ for the free troposphere, and $800 \mathrm{hPa}$ and the surface pressure for the boundary layer, respectively. The units for the integrated moisture and its horizontal flux are kilograms per square meter (or $\mathrm{mm}$ ) and kilograms per meter per second, respectively. The choice of the pressure level separating two layers is to clearly separate the free troposphere from the boundary layer, and is based on the rapid change in the anomaly environmental profiles around $800 \mathrm{hPa}$ as shown in Fig. 6. Note that the top level of the atmospheric boundary layer in the analysis region is generally considered to be around $850 \mathrm{hPa}$, so referring to the lower levels below the 800 -hPa level as the boundary layer in this study is somehow for the sake of convenience. The choice of the pressure level does not alter the key results when changing between 850 and $700 \mathrm{hPa}$ (not shown). The anomalies from the normal condition are calculated as $\left\langle q^{\prime}\right\rangle=\langle q\rangle-\langle\bar{q}\rangle$ and $\left\langle(q \mathbf{u})^{\prime}\right\rangle=\langle q \mathbf{u}\rangle-\langle\bar{q} \bar{u}\rangle$, where the overbars represent the climatological average.

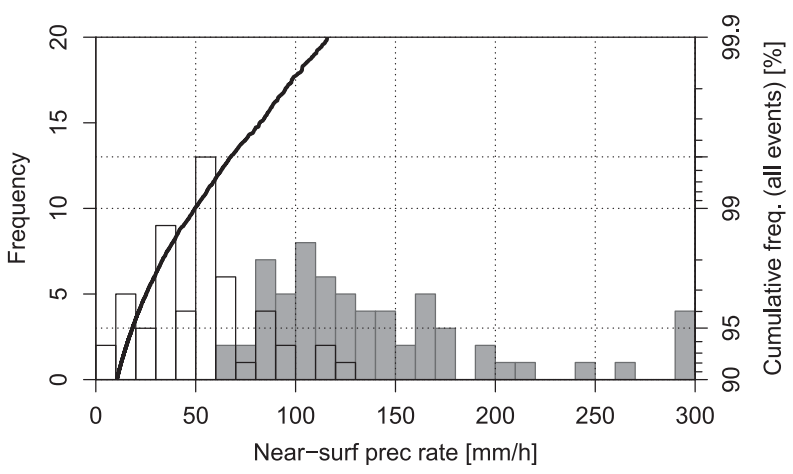

FIG. 4. Relative frequency distributions of the maximum nearsurface rainfall within the rainfall events for R- (gray bars) and $\mathrm{H}$ extreme events (open bars). The solid line shows the cumulative frequency of the maximum near-surface precipitation rates within the rainfall events for all rainfall events (regardless of whether the event is extreme). 


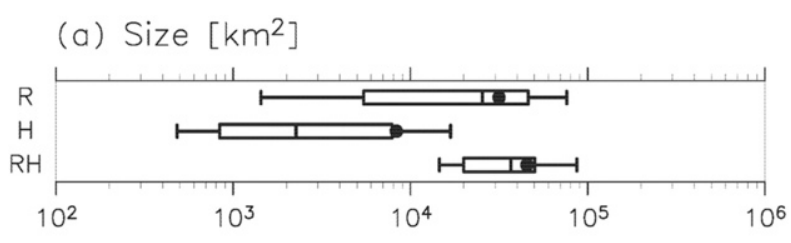

(b) Stratiform area ratio [\%]

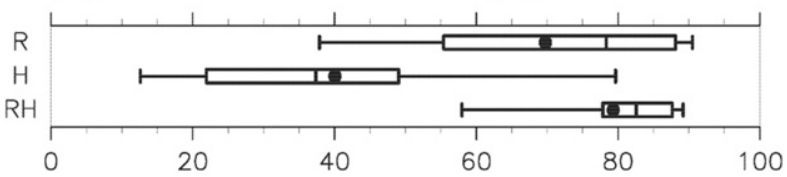

(c) Max 40dBZ echo top height $[\mathrm{km}]$

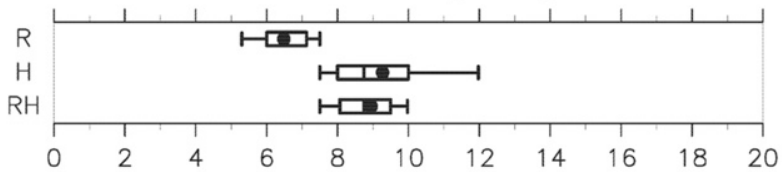

(d) Max prec top height $[\mathrm{km}]$

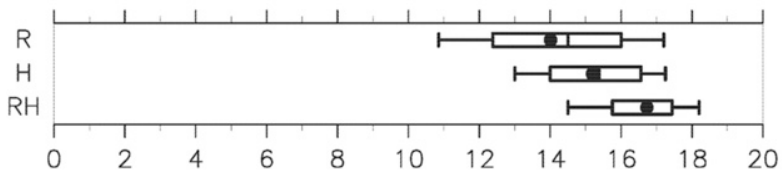

(e) Flash rate [1/convPix/min]

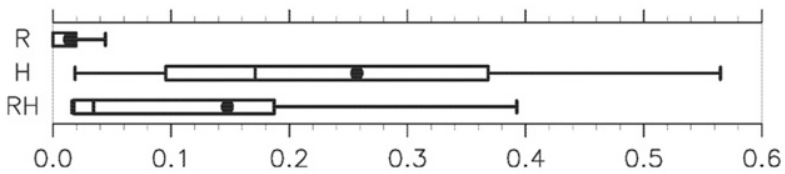

(f) Min PCT85 $[K]$

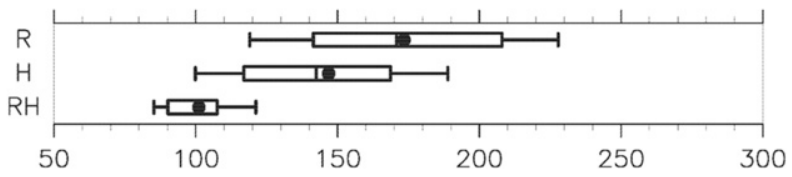

FIG. 5. Box-and-whisker plots of (a) size $\left(\mathrm{km}^{2}\right)$, (b) stratiformarea ratio (\%), (c) maximum $40-\mathrm{dBZ}$ echo-top height $(\mathrm{km})$, (d) maximum precipitation-top height $(\mathrm{km})$, (e) flash rate (per convective pixel per minute), and (f) minimum $85 \mathrm{GHz}$ PCT (K), for $\mathrm{R}-, \mathrm{H}-$, and $\mathrm{RH}$-extreme events. The boxes show the interquartile ranges and medians, the whiskers indicate the ranges from 10 th to 90th percentiles, and filled dots indicate the averages. Note that the statistics on flash rate are calculated from extreme events with LIS viewing time longer than $80 \mathrm{~s}$ (the number of events are 44, 35, and 6 for R-, H-, RH-extreme events, respectively).

It should be mentioned that in this study, we only focus on the large-scale moisture transport in the free troposphere that is vertically integrated over a wide range of the troposphere. Further investigation is required to specify the height range, which is key to the occurrence of the extreme rainfall events and extreme convective events, to make dynamical and physical interpretations.
Anomaly composite maps for the vertically integrated moisture and its horizontal fluxes are shown in Fig. 7. For the R-extreme events, a positive (i.e., moist) anomaly dominates over the extreme event region both in the free troposphere and the boundary layer (Figs. 7a,c). However, the spatial extents of the positive moisture anomaly region are substantially different between the two layers. In the free troposphere, the positive anomaly extends zonally from southern China to the east of Japan. This feature indicates that the excessive moisture in the free troposphere of the composite region can be attributed partially to transportation from the west by a large-scale flow rather than a direct injection by the extreme precipitation event within the region. There is also a negative anomaly region extending zonally, paired with the positive anomaly. A positive anomaly is also observed in the boundary layer and is attributed to southwesterly moisture flux; however, the spatial extent is quite limited compared with that in the free troposphere.

For the $\mathrm{H}$-extreme events, in contrast, negative (i.e., dry) anomalies dominate over the composite region in both the free troposphere and boundary layer (Figs. 7b,d). Moisture fluxes are northwesterly in both layers. Positive anomalies are observed instead on the western and eastern sides of the composite region. The negative anomalous moisture fluxes both in the boundary layer and free troposphere over the composite region might seem against the general understanding that moisture inflow at the boundary layer is essential to the initiation and formation of heavy rainfall events over Japan. Further detailed study is needed, but this is partly because about $65 \%$ of the $\mathrm{R}$ - and $\mathrm{H}$-extreme events occurred over the sea, where forced lifting of moisture inflow at the lowest level by the topography is not essential to the initiation of convection, or is simply because smaller-scale flows are not resolved in the reanalysis dataset used in this study. An interesting feature that contrasted with R-extreme events is seen in the free troposphere west of $110^{\circ} \mathrm{E}$, where a significant positive moisture anomaly dominates north of $30^{\circ} \mathrm{N}$ and a significant negative anomaly dominates south of $30^{\circ} \mathrm{N}$. The patterns of anomalous circulation and temperature in the middle-upper troposphere in this region associated with the $\mathrm{H}$-extreme events (not shown) are quite similar to those associated with the "warm heavy rainfall days" that are determined by Sun et al. (2015, their Figs. 3a,c) over central north China. This possibly indicates a dynamical link between the $\mathrm{H}$-extreme events over southern Japan and warm-type heavy rainfall events over central north China.

The differences between the vertically integrated moisture anomalies associated with $\mathrm{R}$ - and $\mathrm{H}$-extreme 
(a) $\mathrm{T}$

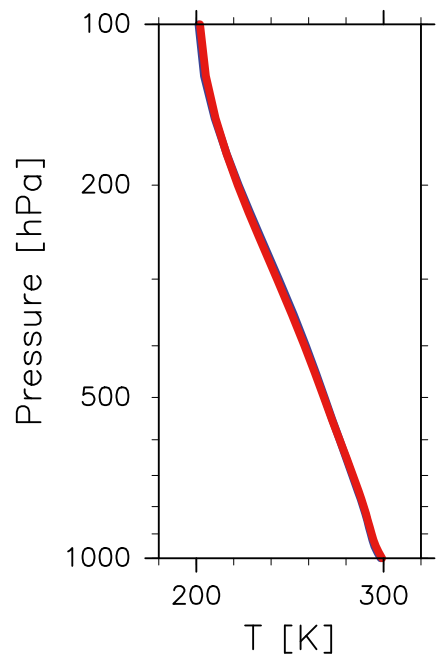

(e) $T^{\prime}$

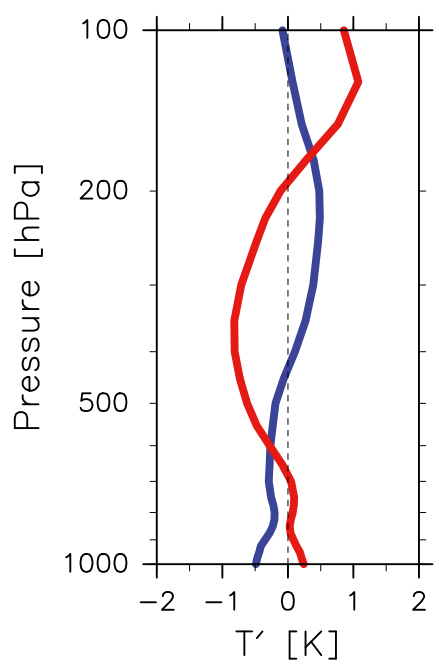

(b) EPT

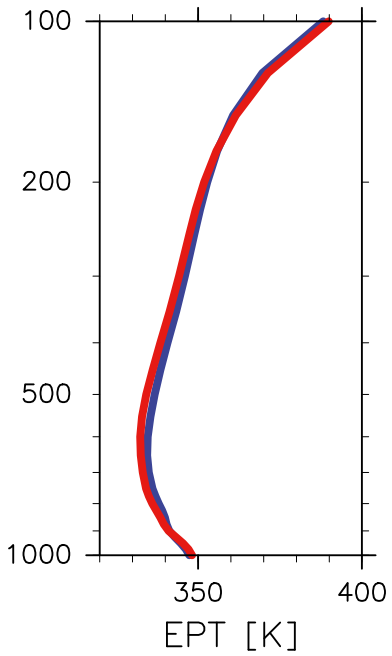

(f) $\mathrm{EPT}^{\prime}$

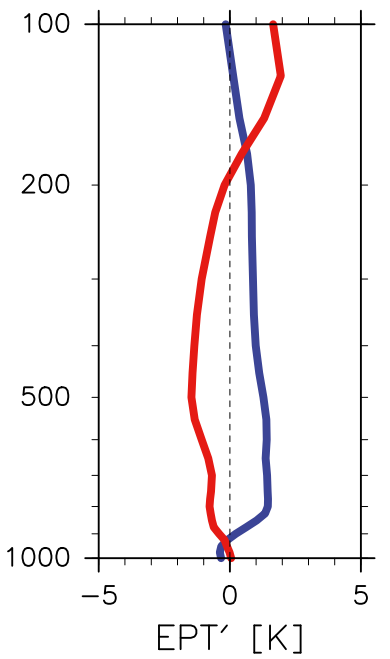

(c) $\mathrm{RH}$

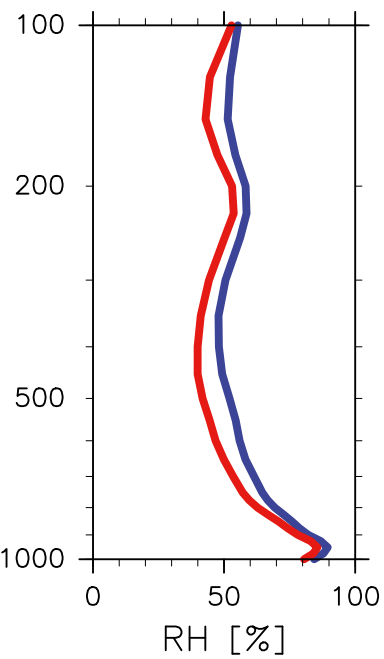

(g) $\mathrm{RH}^{\prime}$

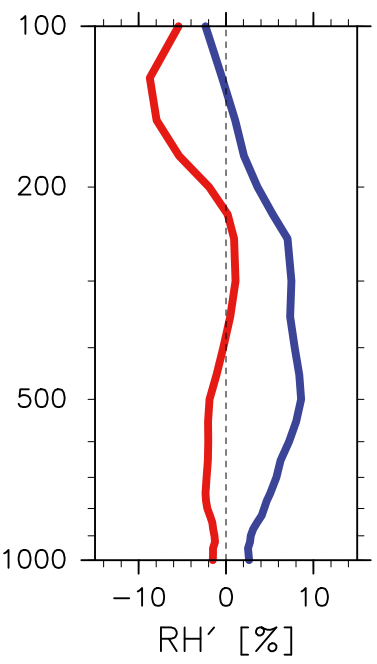

(d) $q$

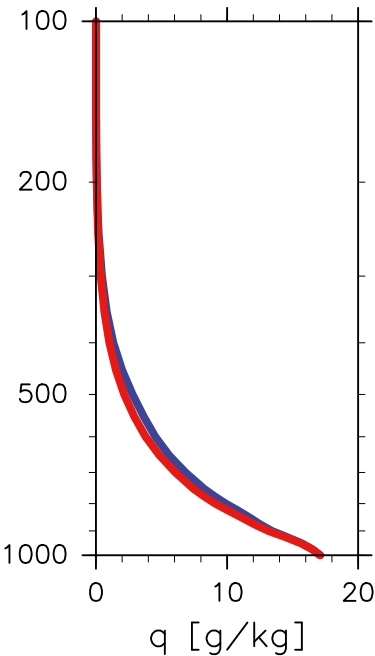

(h) $q^{\prime}$

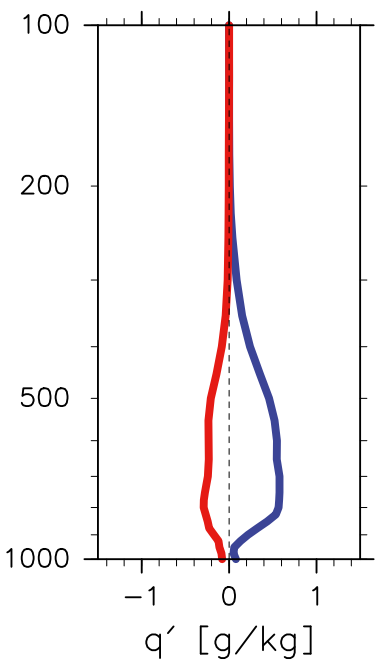

FIG. 6. Composite vertical profiles of (a),(e) equivalent potential temperature, (b),(f) temperature, (c),(g) relative humidity, and (d),(h) specific humidity for R- (blue) and H-extreme events (red). Upper panels show raw values, and lower panels show anomalies from the climatology.

events are shown in Fig. 8. The difference in the free troposphere (Fig. 8a; differences between Figs. 7a and 7b) shows a statistically significant positive moisture anomaly extending from southern China to the east of Japan. The difference in the boundary layer (Fig. 8b; differences between Figs. 7c and 7d) is clearly different from that in the free troposphere and the spatial extent is limited around the composite key region.

The free-tropospheric moisture anomalies related to R-extreme events primarily contribute to the total column water vapor anomaly. Figure 9 shows the fraction of $\left\langle q^{\prime}\right\rangle_{\mathrm{FT}}$ to the total column water vapor, $\left\langle q^{\prime}\right\rangle_{\mathrm{FT}}+\left\langle q^{\prime}\right\rangle_{\mathrm{BL}}$. The free-tropospheric moisture anomaly explains more than $70 \%$ of the total column vapor anomaly in most of the region where a positive moisture anomaly is observed (Fig. 7a). This feature indicates the importance of free-tropospheric moisture in producing the extreme rainfall events and is consistent with the result of a previous case study (Hirota et al. 2016).

Some extreme events are directly or indirectly related to tropical cyclones (TCs). However, the relationship between the extreme events and the TCs is different for different types of extreme events. Figure 10 shows the frequency distributions of the distances between the extreme events and the center of the nearest TCs. An extreme event is defined to be related to TC when it is located within $4000 \mathrm{~km}$ of a TC center, derived from the International Best Track Archive for Climate 
(a) R-extreme $\left\langle q^{\prime}\right\rangle$, $\left\langle(q u)^{\prime}\right\rangle(100-800 h P a)$

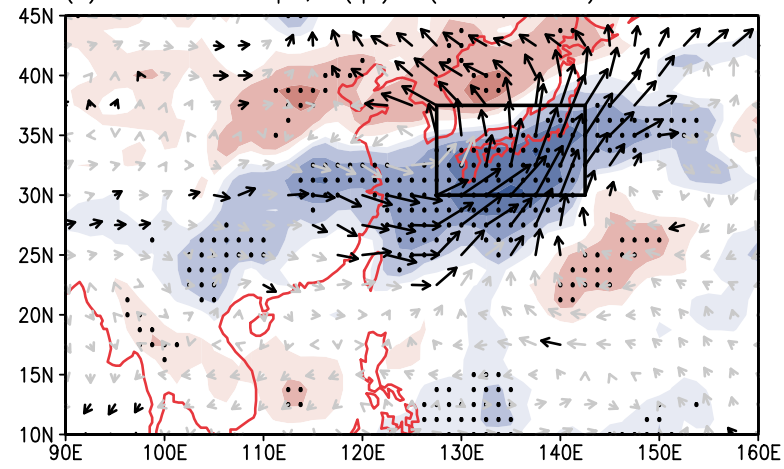

(c) $\mathrm{R}$-extreme $\left\langle\mathrm{q}^{\prime}\right\rangle$, $\left\langle(\mathrm{qu})^{\prime}\right\rangle(800 \mathrm{hPa}-\mathrm{sfc})$

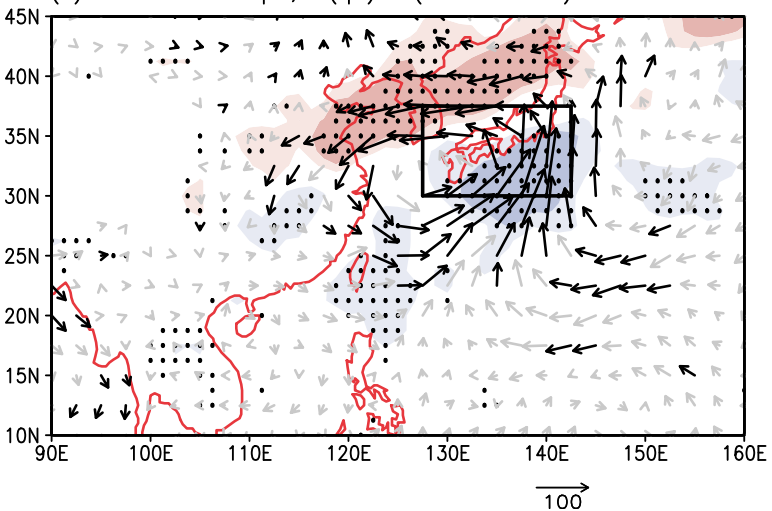

(b) $\mathrm{H}$-extreme $\left\langle\mathrm{q}^{\prime}\right\rangle$, $\left\langle(\mathrm{qu})^{\prime}\right\rangle(100-800 \mathrm{hPa})$

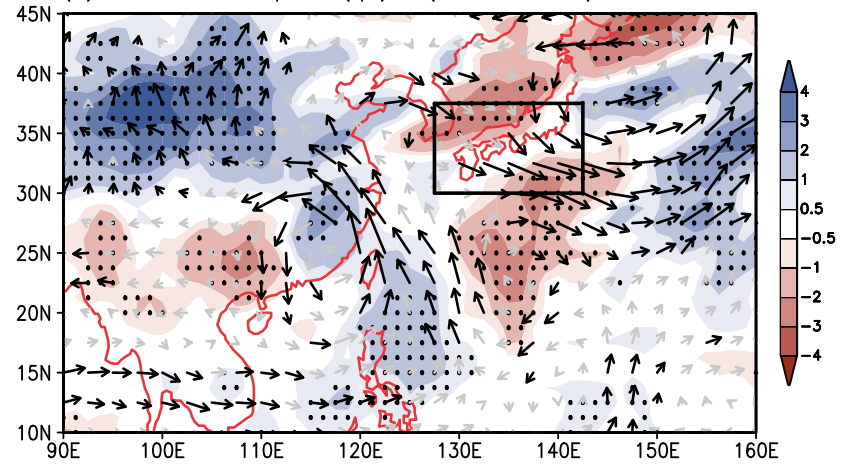

(d) $\mathrm{H}$-extreme $\left\langle\mathrm{q}^{\prime}\right\rangle,\left\langle(\mathrm{qu})^{\prime}\right\rangle(800 \mathrm{hPa}-\mathrm{sfc})$

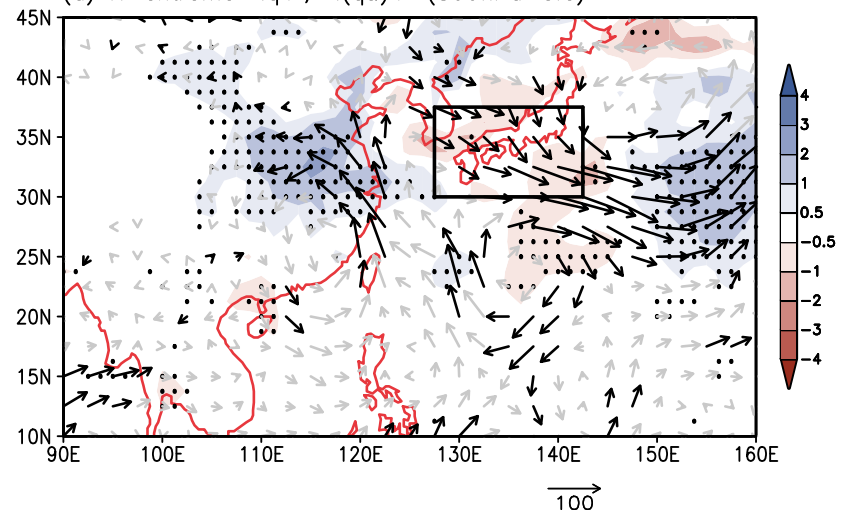

FIG. 7. Composite maps of vertically integrated moisture and its horizontal flux for (a),(c) the R- and (b),(d) H-extreme events. Shown are the results for (top) the free troposphere (between 100 and $800 \mathrm{hPa}$ ) and (bottom) the boundary layer (between $800 \mathrm{hPa}$ and the surface). All values are shown as the anomaly from the climatological average. Colors indicate the moisture anomaly (mm) and vectors indicate the horizontal moisture flux anomaly $\left(\mathrm{kg} \mathrm{m}^{-1} \mathrm{~s}^{-1}\right)$. Dots indicate the grid points where the moisture anomalies are statistically significant at a $95 \%$ confidence level using the Student's $t$ test. Black and gray vectors indicate the moisture flux anomalies that are statistically significant and are not statistically significant using the Student's $t$ test, respectively. The solid rectangle indicates the composite key region.

Stewardship (IBTrACS) dataset (Knapp et al. 2010). About $80 \%$ and $77 \%$ of the R- and H-extreme events, respectively, are related to the TCs either directly or indirectly. However, only about $25 \%$ and $5 \%$ of the $\mathrm{R}$ - and H-extreme events occur within $500 \mathrm{~km}$ of a TC center, indicating that only a small fraction of the extreme events are directly related to the TCs, such as distinct rainbands. It is noteworthy that there is a maximum of around $2000 \mathrm{~km}$ for the $\mathrm{H}$-extreme events, implying some indirect effects of TCs in producing the extreme convective events. Distribution for the R-extreme events also has broad, secondary maxima of around 1200 and $2000-2800 \mathrm{~km}$. Visual inspection indicates that in some cases there is a strong southerly moisture flux in both the free troposphere and the boundary layer, consistent with a mechanism proposed in previous studies (Yoshida and Itoh 2012; Cordeira et al. 2013).

It would be worthy to note again that three-fourths of the R-extreme events are not directly related to the TCs.
This indicates that moisture transport in the free troposphere by large-scale flow is a primary factor in producing the extreme rainfall events. Figure 11 shows the composite map, as in Fig. 7, but only for the R-extreme events more than $500 \mathrm{~km}$ from the nearest TC center. A zonally extending positive anomaly region in the free troposphere is observed more clearly (Fig. 11a). The anomalous cyclonic circulation in the boundary layer to the southwest can still be observed, but the circulation is much weaker and smaller than that in Fig. 7c, and is not statistically significant (Fig. 11b). The southerly moisture flux anomaly is more limited than that in Fig. 7c. By visual inspection of each of the R-extreme events, in many cases, there is a long, thin structure that originates in the east of the Tibetan Plateau and extends along the meandering subtropical jet stream. This is reminiscent of the AR.

Upper-tropospheric dynamical fields related to R-and $\mathrm{H}$-extreme events also show clear differences. Figure 12 shows composite anomaly fields of pressure 
(a) $\left\langle q^{\prime}\right\rangle$ difference $(\mathrm{R}-\mathrm{H})(100-800 \mathrm{hPa})$

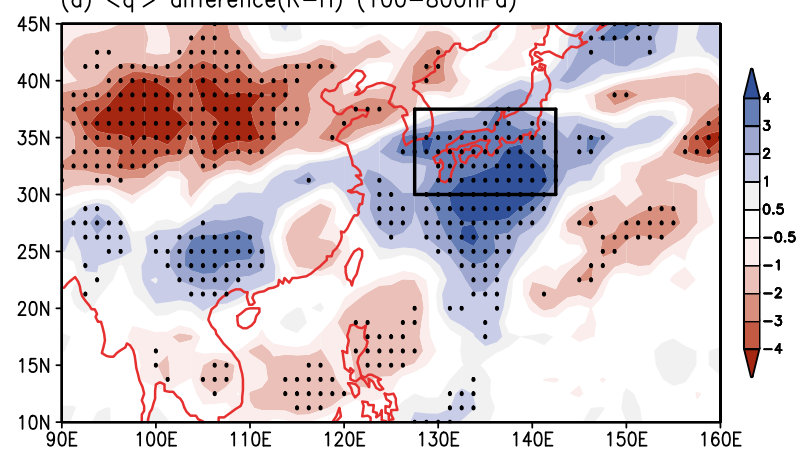

(b) $\left\langle q^{\prime}\right\rangle$ difference $(\mathrm{R}-\mathrm{H})(800-\mathrm{sfc})$

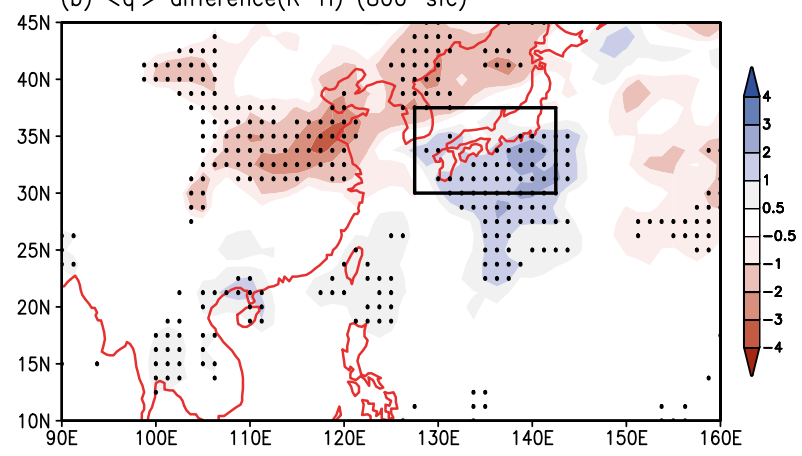

FIG. 8. Differences between the vertically integrated moisture anomalies associated with $\mathrm{R}$-extreme events and $\mathrm{H}$-extreme events for (a) the free troposphere (between 100 and $800 \mathrm{hPa}$ ) and (b) the boundary layer (between $800 \mathrm{hPa}$ and the surface). The units are $\mathrm{mm}$. Dots indicate the grid points where the differences of the moisture anomalies are statistically significant at a $95 \%$ confidence level using the Student's $t$ test. The solid rectangle indicates the composite key region.

vertical velocity at $500 \mathrm{hPa}$ and geopotential height at $200 \mathrm{hPa}$, along with a 2-PVU (1 PVU $\left.=10^{-6} \mathrm{~K} \mathrm{~kg}^{-1} \mathrm{~m}^{2} \mathrm{~s}^{-1}\right)$ isopleth of potential vorticity at $350 \mathrm{~K}$ as an index of the subtropical jet's location (Horinouchi 2014). For the $\mathrm{R}$-extreme events, the upper-level trough is located west of the composite region (Fig. 12a). The height anomaly is negative and positive in the north and south, respectively. The corresponding horizontal wind anomaly is more zonal and anticyclonic on the southern side of the jet. These features in the anomalous wind field are likely to be favorable for transporting a warm and humid tropical air mass into the target region (Fig. 11a). The pressure vertical velocity anomaly is negative over the entire composite region, and extends along the southern side of the meandering jet. This may indicate an importance of secondary circulation associated with geostrophic flow (Horinouchi and Hayashi 2017) to produce a favorable environment for extreme precipitation events, although there is a very weak positive anomaly that is expected to occur in pairs. For the $\mathrm{H}$-extreme events, in contrast, the upper-level trough is

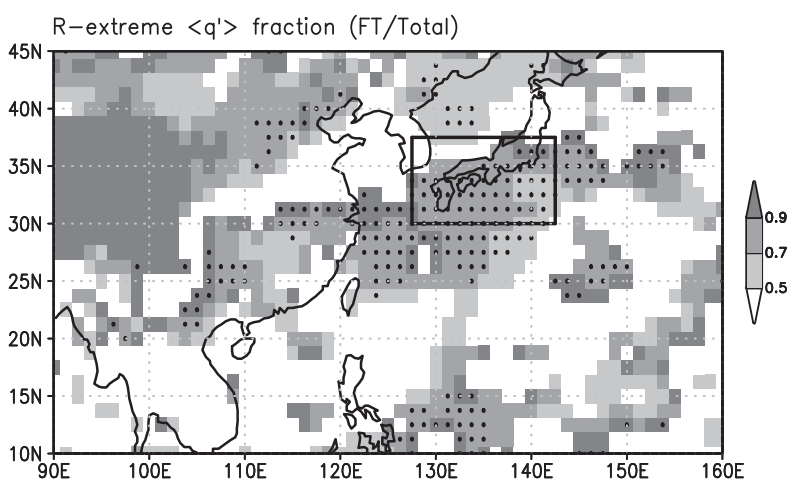

FIG. 9. Fraction of free-tropospheric moisture anomaly to the total column moisture for the R-extreme events. Shading is used only for the region where the signs of the anomalies are the same between the free troposphere and the boundary layer. Dots indicate the grid points where the moisture anomalies are statistically significant at a $95 \%$ confidence level using the Student's $t$ test.

located, although not clearly, over almost the entire composite region (Fig. 12b). The target region is under a negative height anomaly that is a part of wave-like height anomalies along the jet axis. A corresponding anomalous horizontal wind is northerly in the west of the target region. Such an anomalous circulation pattern causes the drier free-tropospheric environment related to $\mathrm{H}$-extreme events (Fig. 7c).

\section{Discussion and concluding remarks}

The relationship between the precipitation characteristics and large-scale environmental conditions related to extreme events were determined from 13 years of TRMM PR measurements. Two types of extreme events, $\mathrm{R}$ - and $\mathrm{H}$-extreme events, were defined for each $2.5^{\circ} \times 2.5^{\circ}$ grid cell to properly capture the regional differences of the precipitation characteristics, and their characteristic differences were examined.

There were significant differences in precipitation characteristics between $\mathrm{R}$ - and $\mathrm{H}$-extreme events, which were basically consistent with the result of a global analysis by H15. Vertical profiles of radar reflectivity of $\mathrm{R}$-extreme events had relatively lower echo-top heights compared with $\mathrm{H}$-extreme events, and exhibited a linear downward increase below the melting level. These characteristics imply an importance of warm-rain processes in the precipitation production. Precipitation characteristics, such as size, stratiform-area ratio, and flash rates, also showed clear differences between the $\mathrm{R}$ - and $\mathrm{H}$-extreme events. R-extreme events basically exhibited a larger size and higher stratiform-area ratio, indicating that $\mathrm{R}$-extreme events consisted of more organized precipitation systems. The maximum $40-\mathrm{dB} Z$ 


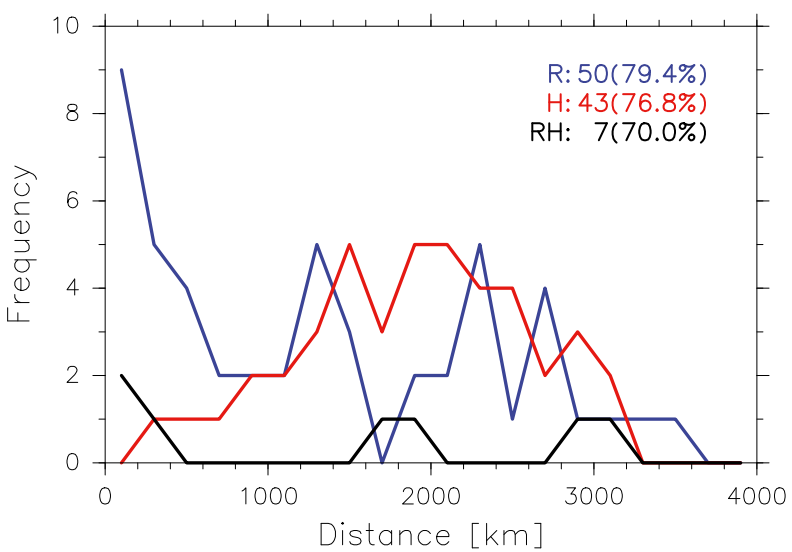

FIG. 10. Frequency distributions of the distances between the extreme events and the center of the nearest TC. Blue, red, and black lines show the frequencies for R-, H-, and RH-extreme events, respectively. The numbers of the extreme events related to the TCs and the percentages of them among all the corresponding types of extreme events are indicated.

echo-top heights of R-extreme events were significantly lower than those of $\mathrm{H}$-extreme events, whereas the contrast in the highest precipitation-top heights between $\mathrm{R}$ - and $\mathrm{H}$-extreme events was not so clear. These results were reflected in the distributions of flash rates and minimum PCT85; flash rates showed a very large difference, whereas minimum PCT85 showed a not-sosignificant difference.

Frequency distributions of maximum precipitation rates $\left(R_{\max }\right)$ of $\mathrm{R}$ - and $\mathrm{H}$-extreme events were clearly separated. The lowest value of $R_{\max }$ for $\mathrm{R}$-extreme events almost corresponded to the highest value of $R_{\max }$ for $\mathrm{H}$-extreme events. An important result was that thresholding values often used to statistically define "heavy rainfall" or "intense precipitation" in $1 \mathrm{~h}$ or less in the Japan region included both of R-and a majority of $\mathrm{H}$-extreme events.

Large-scale environmental conditions related to $\mathrm{R}$ - and H-extreme events showed clear differences, especially in the free troposphere above the $800-\mathrm{hPa}$ level. Environments related to R-extreme events exhibited lower and warmer equivalent potential temperature in the boundary layer and free troposphere, respectively, indicating somewhat convectively stable conditions in the lower troposphere compared with the climatological condition. Both relative humidity and specific humidity were higher in almost the entire troposphere, especially in the free troposphere. Such a humid condition for R-extreme events was not locally limited, but had large spatial extents. In the free troposphere, the positive anomaly of vertically integrated water vapor extended zonally from southern China to the east of Japan, indicating that the excessive moisture was transported (c) R-extreme $\left.\left\langle\mathrm{q}^{\prime}\right\rangle,\left\langle(\mathrm{qu})^{\prime}\right\rangle(100-800 \mathrm{hPa}) \mathrm{TC}\right\rangle 500 \mathrm{~km}$

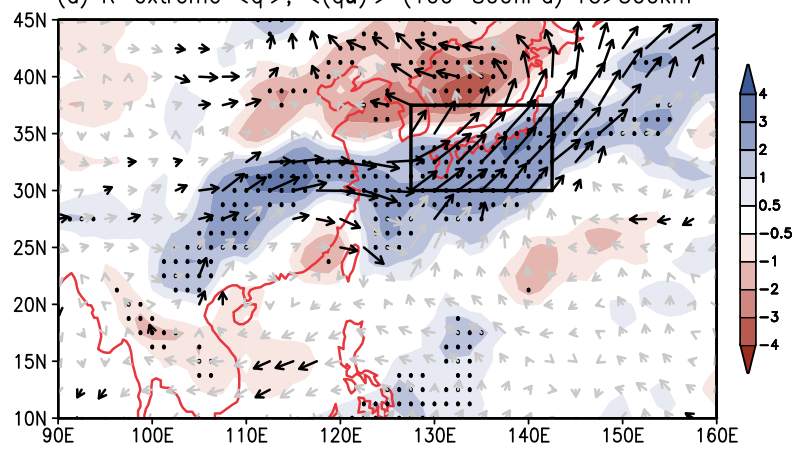

(b) R-extreme $\left.\left\langle q^{\prime}\right\rangle,\left\langle(q u)^{\prime}\right\rangle(800 \mathrm{hPa}-\mathrm{sfc}) \mathrm{TC}\right\rangle 500 \mathrm{~km}$

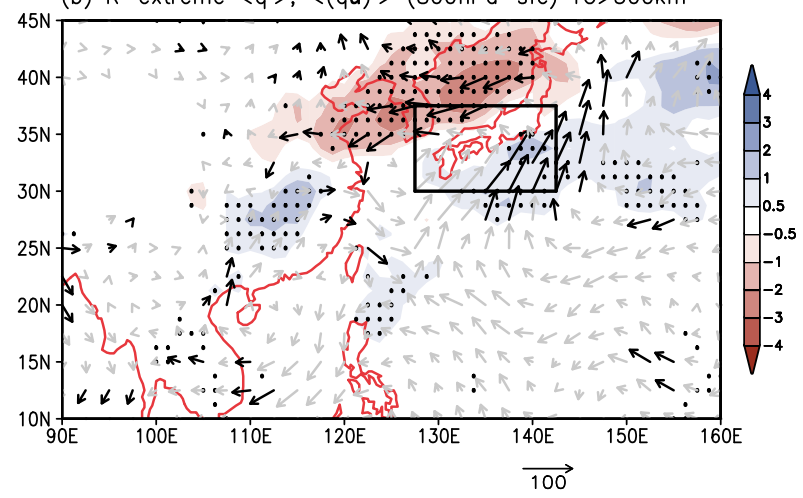

FIG. 11. As in Figs. 7a and 7c, but only for the R-extreme events with the distances from the nearest TC centers larger than $500 \mathrm{~km}$.

from the west by a large-scale flow. A positive anomaly was also observed in the boundary layer, as expected, but the spatial extent was quite limited. The free-tropospheric moisture anomalies related to R-extreme events explained more than $70 \%$ of the total column water vapor anomaly, indicating an importance of free-tropospheric moisture to produce the extreme rainfall events.

Some extreme events were directly or indirectly related to the TCs. About one-fourth of the R-extreme events occurred within $500 \mathrm{~km}$ of a TC center, while only $5 \%$ of the H-extreme events occurred within $500 \mathrm{~km}$ of a TC center. Visual inspection indicated that some R-extreme events seemed to be indirectly affected by TCs because of a strong southerly moisture flux in the free troposphere.

Dynamical fields in the upper troposphere showed clear differences between $\mathrm{R}$ - and H-extreme events. $\mathrm{R}$-extreme events were associated with negative and positive height anomalies in the north and south at $200 \mathrm{hPa}$, respectively. Corresponding wind fields were likely to be favorable for producing the extreme rainfall events. H-extreme events, in contrast, were under a negative height anomaly that was a part of wave-like height anomalies along the subtropical jet axis.

It should be noted that there is some possibility that some of the R-extreme events correspond to different 
(a) R-extreme $\omega 500$, Z200, 2PVU@350K, TC > 500km

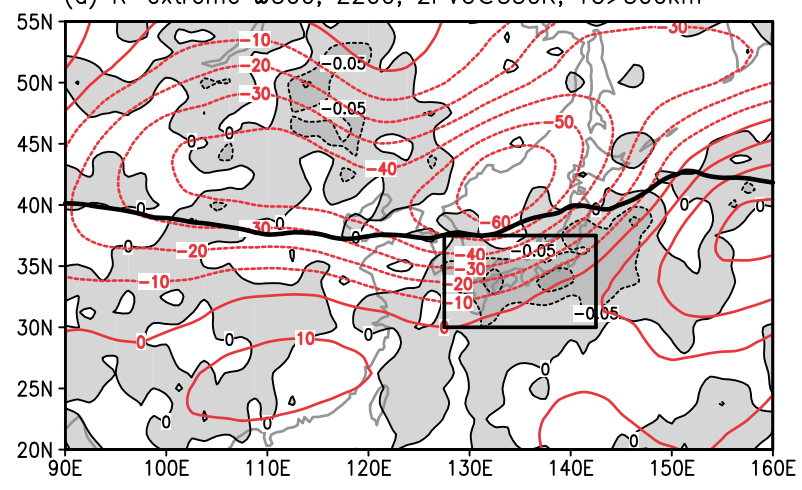

(b) H-extreme $\omega 500, Z 200,2 \mathrm{PVU} @ 350 \mathrm{~K}, \mathrm{TC}>500 \mathrm{~km}$

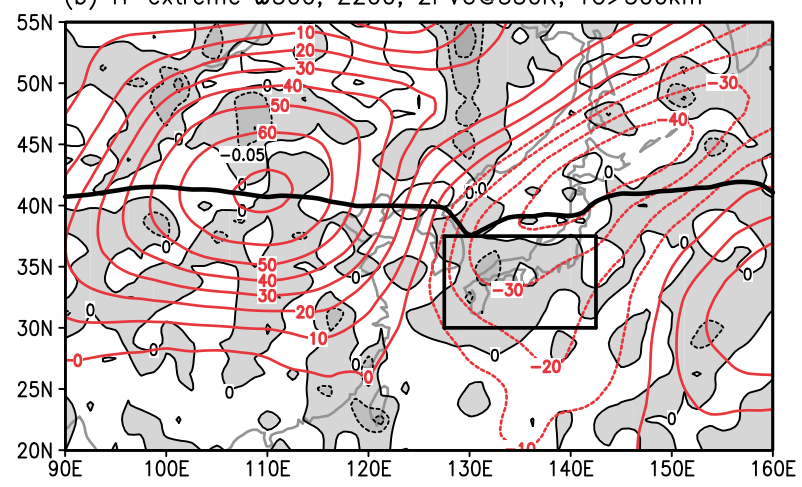

FIG. 12. As in Fig. 11, but for anomalies of pressure vertical velocity at $500 \mathrm{hPa}$ (black contours, negative area shaded) and geopotential height at $200 \mathrm{hPa}$ (red contours). The bold solid line indicates the 2-PVU isopleth of potential vorticity at $350 \mathrm{~K}$. Note the latitudinal range is slightly different from that of Fig. 11.

developing stages of convective systems related to $\mathrm{H}-$ extreme events. In typical severe multicell storms, precipitation particles often can grow aloft to large graupels or hailstones within strong updraft (Browning et al. 1976; Houze 2014, section 8.2). In this case, the centroids of strong radar echoes can be in the upper and lower troposphere before and after the hail start to fall toward the ground, respectively, and the vertical $Z_{e}$ profiles at these stages may be similar to those of the $\mathrm{H}$-extreme and R-extreme events, respectively.

It was demonstrated that a variety of large-scale disturbances from the tropics to midlatitudes was related to both $\mathrm{R}$ - and $\mathrm{H}$-extreme events. Further analysis should be performed to quantify the relative contributions of these disturbances and to understand how the processes of these disturbances cause conditions favorable to extreme rainfall and extreme convective events.

Acknowledgments. The authors are grateful to Dr. Nagio Hirota of the National Institute for Environmental Studies, Japan, for his help in preparing the JRA-55 dataset. This study was supported by the Environment Research and Technology Development Fund (2-1503) of Environmental Restoration and Conservation Agency, Japan, the Grants-in-Aid for Scientific Research (15H02132) of the Japan Society for the Promotion of Science, and the 8th GPM/TRMM RA of the Japan Aerospace Exploration Agency (JAXA), Japan. Figures have been produced using the GFD-DENNOU Library and the Grid Analysis and Display System (GrADS), using color maps recommended by Inatsu and Hamada (2016; an online color map generator is available at http://reccahokkaido.sci.hokudai.ac.jp/ inaz/colour/).

\section{REFERENCES}

Blakeslee, R. J., 1998: Lightning Imaging Sensor (LIS) on TRMM science data. NASA Global Hydrology Center DAAC, accessed 17 April 2018, http://doi.org/10.5067/LIS/ LIS/DATA201.

Browning, K. A., and Coauthors, 1976: Structure of an evolving hailstorm, P V: Synthesis and implications for hail growth and hail suppression. Mon. Wea. Rev., 104, 603-610, https://doi.org/ 10.1175/1520-0493(1976)104<0603:SOAEHP>2.0.CO;2.

Cordeira, J. M., F. M. Ralph, and B. J. Moore, 2013: The development and evolution of two atmospheric rivers in proximity to western North Pacific tropical cyclones in October 2010. Mon. Wea. Rev., 141, 4234-4255, https://doi.org/10.1175/ MWR-D-13-00019.1.

Farr, T. G., and Coauthors, 2007: The Shuttle Radar Topography Mission. Rev. Geophys., 45, RG2004, https://doi.org/10.1029/ 2005RG000183.

Fujibe, F., 1999: Diurnal variation in the frequency of heavy precipitation in Japan. J. Meteor. Soc. Japan, 77, 1137-1149, https://doi.org/10.2151/jmsj1965.77.6_1137.

— , 2015: Relationship between interannual variations of extreme hourly precipitation and air/sea-surface temperature in Japan. SOLA, 11, 5-9, https://doi.org/10.2151/sola.2015-002.

Gimeno, L., R. Nieto, M. Vázquez, and D. A. Lavers, 2014: Atmospheric rivers: A mini-review. Front. Earth Sci., 2, https:// doi.org/10.3389/feart.2014.00002.

Hamada, A., and Y. N. Takayabu, 2014: A removal filter for suspicious extreme rainfall profiles in TRMM PR 2A25 version-7 data. J. Appl. Meteor. Climatol., 53, 1252-1271, https://doi.org/ 10.1175/JAMC-D-13-099.1.

_, Y. Murayama, and Y. N. Takayabu, 2014: Regional characteristics of extreme rainfall extracted from TRMM PR measurements. J. Climate, 27, 8151-8169, https://doi.org/ 10.1175/JCLI-D-14-00107.1.

_ - Y. N. Takayabu, C. Liu, and E. J. Zipser, 2015: Weak linkage between the heaviest rainfall and tallest storms. Nat. Commun., 6, 6213, https://doi.org/10.1038/ncomms7213.

Hirose, M., Y. N. Takayabu, A. Hamada, S. Shige, and M. K. Yamamoto, 2017: Impact of long-term observation on the sampling characteristics of TRMM PR precipitation. J. Appl. Meteor. Climatol., 56, 713-723, https://doi.org/10.1175/ JAMC-D-16-0115.1.

Hirota, N., Y. N. Takayabu, M. Kato, and S. Arakane, 2016: Roles of an atmospheric river and a cutoff low in the extreme precipitation event in Hiroshima on 19 August 2014. Mon. Wea. Rev., 144, 1145-1160, https://doi.org/10.1175/MWR-D-15-0299.1. 
Horinouchi, T., 2014: Influence of upper tropospheric disturbances on the synoptic variability of precipitation and moisture transport over summertime East Asia and the northwestern Pacific. J. Meteor. Soc. Japan, 92, 519-541, https://doi.org/ 10.2151/jmsj.2014-602.

— , and A. Hayashi, 2017: Meandering subtropical jet and precipitation over summertime East Asia and the northwestern Pacific. J. Atmos. Sci., 74, 1233-1247, https://doi.org/10.1175/ JAS-D-16-0252.1.

Houze, R. A., Jr., 2014: Cloud Dynamics. 2nd ed. Academic Press, 432 pp.

Iguchi, T., T. Kozu, R. Meneghini, J. Awaka, and K. Okamoto, 2000: Rain-profiling algorithm for the TRMM Precipitation Radar. J. Appl. Meteor., 39, 2038-2052, https://doi.org/10.1175/ 1520-0450(2001)040<2038:RPAFTT>2.0.CO;2.

- - - J. Kwiatkowski, R. Meneghini, J. Awaka, and K. Okamoto, 2009: Uncertainties in the rain profiling algorithm for the TRMM Precipitation Radar. J. Meteor. Soc. Japan, 87A, 1-30, https://doi.org/10.2151/jmsj.87A.1.

Inatsu, M., and A. Hamada, 2016: Coloring in meteorology with uniform color space (in Japanese). Tenki, 63 , 803-809.

IPCC, 2013: Climate Change 2013: The Physical Science Basis. Cambridge University Press, 1535 pp., https://doi.org/10.1017/ CBO9781107415324.

JMA, 2017: Climate change monitoring report 2016. Japan Meteorological Agency, https://www.jma.go.jp/jma/en/NMHS/ indexe_ccmr.html.

Kamae, Y., W. Mei, S.-P. Xie, M. Naoi, and H. Ueda, 2017: Atmospheric rivers over the northwestern Pacific: Climatology and interannual variability. J. Climate, 30, 5605-5619, https:// doi.org/10.1175/JCLI-D-16-0875.1.

Kato, T., and H. Goda, 2001: Formation and maintenance processes of a stationary band-shaped heavy rainfall observed in Niigata on 4 August 1998. J. Meteor. Soc. Japan, 79, 899-924, https://doi.org/10.2151/jmsj.79.899.

, and K. Aranami, 2005: Formation factors of 2004 NiigataFukushima and Fukui heavy rainfalls and problems in the predictions using a cloud-resolving model. SOLA, 1, 1-4, https://doi.org/10.2151/sola.2005-001.
Knapp, K. R., M. C. Kruk, D. H. Levinson, H. J. Diamond, and C. J. Neumann, 2010: The International Best Track Archive for Climate Stewardship (IBTrACS): Unifying tropical cyclone data. Bull. Amer. Meteor. Soc., 91, 363-376, https://doi.org/ 10.1175/2009BAMS2755.1.

Kobayashi, S., and Coauthors, 2015: The JRA-55 reanalysis: General specifications and basic characteristics. J. Meteor. Soc. Japan, 93, 5-48, https://doi.org/10.2151/jmsj.2015-001.

Sohn, B. J., G.-H. Ryu, H.-J. Song, and M.-L. Ou, 2013: Characteristic features of warm-type rain producing heavy rainfall over the Korean peninsula inferred from TRMM measurements. Mon. Wea. Rev., 141, 3873-3888, https://doi.org/ 10.1175/MWR-D-13-00075.1.

Sun, W., J. Li, R. Yu, and W. Yuan, 2015: Two major circulation structures leading to heavy summer rainfall over central North China. J. Geophys. Res. Atmos., 120, 4466-4482, https://doi.org/ 10.1002/2014JD022853.

Unuma, T., and T. Takemi, 2016: Characteristics and environmental conditions of quasi-stationary convective clusters during the warm season in Japan. Quart. J. Roy. Meteor. Soc., 142, 1232-1249, https://doi.org/10.1002/qj.2726.

Waliser, D., and B. Guan, 2017: Extreme winds and precipitation during landfall of atmospheric rivers. Nat. Geosci., 10, 179183, https://doi.org/10.1038/ngeo2894.

Yang, W., and I. Zurbenko, 2010: Kolmogorov-Zurbenko filters. Wiley Interdiscip. Rev.: Comp. Stat, 2, 340-351, https://doi.org/ 10.1002/wics.71.

Yokoyama, C., Y. N. Takayabu, and T. Horinouchi, 2017: Precipitation characteristics over East Asia in early summer: Effects of the subtropical jet and lower-tropospheric convective instability. J. Climate, 30, 8127-8147, https://doi.org/10.1175/ JCLI-D-16-0724.1.

Yoshida, K., and H. Itoh, 2012: Indirect effects of tropical cyclones on heavy rainfall events in Kyushu, Japan, during the baiu season. J. Meteor. Soc. Japan, 90, 377-401, https://doi.org/ 10.2151/jmsj.2012-303.

Zhu, Y., and R. E. Newell, 1998: A proposed algorithm for moisture fluxes from atmospheric rivers. Mon. Wea. Rev., 126, 725-735, https://doi.org/10.1175/1520-0493(1998)126<0725: APAFMF $>2.0 . \mathrm{CO} ; 2$ 